\title{
Impact of COVID-19 Lockdown on Maternal Psychological Status, The Couple's Relationship and Mother-Child Interaction: A Prospective Study.
}

\section{Sylvie Viaux Savelon}

AP-HP .Sorbonne Université, Department of Child and Adolescent Psychiatry, Pitié-Salpêtrière Hospital, Paris

\section{Paul Maurice}

AP-HP .Sorbonne Université, Fetal Medicine Department, Armand Trousseau Hospital, Paris

\section{Alexandra Rousseau}

AP-HP .Sorbonne Université, URCEST, Paris

\section{Chloé Laufer}

AP-HP .Sorbonne Université, Obstetrics and Gynecology Department, Tenon Hospital, Paris

\section{Manon Renout}

AP-HP .Sorbonne Université, Department of Child and Adolescent Psychiatry, Pitié-Salpêtrière Hospital,

Paris

\section{Laura Berlingo}

AP-HP .Sorbonne Université, Obstetrics and Gynecology Department, Pitié-Salpêtrière Hospital, Paris

\section{David Cohen}

AP-HP .Sorbonne Université, Department of Child and Adolescent Psychiatry, Pitié-Salpêtrière Hospital, Paris

Jean-Marie Jouannic ( $\nabla$ jean-marie.jouannic@aphp.fr)

AP-HP .Sorbonne Université, Fetal Medicine Department, Armand Trousseau Hospital, Paris

\section{Research Article}

Keywords: Covid-19, pregnancy, lockdown, depression, anxiety, post-traumatic stress, mother-child interaction

Posted Date: February 14th, 2022

DOI: https://doi.org/10.21203/rs.3.rs-1310138/v1

License: (c) (i) This work is licensed under a Creative Commons Attribution 4.0 International License.

Read Full License 


\section{Abstract}

Background: To compare the rate of postpartum depression (PPD) during the first COVID-19 lockdown with the rate observed prior to the pandemic, and to examine factors associated with PPD.

Methods: This was a prospective study. Women who gave birth during the first COVID-19 lockdown (spring 2020) were offered call-interviews at 10 days and 6-8 weeks postpartum to assess PPD using the Edinburgh Postnatal Depression Scale (EPDS). Post-traumatic symptoms (Perinatal Post-traumatic Stress Disorder Questionnaire, PPQ), couple adjustment, and interaction and mother-to-infant bonding were also evaluated. The observed PPD rate was compared to the one reported before the pandemic. Factors associated with an increased risk of PPD were studied. The main outcome measures were comparison of the observed PPD rate (EPDS score>12) to pre-pandemic rate.

Results: Of the 164 women included, 27 (16.5\% [95\% Cl: 11.14 - 23.04]) presented an EPDS score $>12$ either at 10 days or 6-8 weeks postpartum. This rate was similar to the one of $15 \%$ reported prior to the pandemic $(p=0.6)$. Combined EPDS $>12$ or PPQ $>6$ scores were observed in $20.7 \%$ of the mothers [ $95 \% \mathrm{Cl}$ : $14.8-0.28]$. Maternal hypertension/preeclampsia $(p=0.007)$, emergency cesarean section $(p=0.03)$, and neonatal complications $(p=0.008)$ were significantly associated with an EPDS $>12$ both in univariate and multivariate analysis (OR=10 [95\%Cl: $1.5-68.7$ ], $\mathrm{OR}=4.09[95 \% \mathrm{Cl}: 1.2-14]$ ], OR=4.02[95\%Cl: $1.4-11.6]$, respectively).

Conclusions: The rate of major PPD in our population did not increase during the first lockdown period. However, $20.7 \%$ of the women presented with post-traumatic/depressive symptoms.

\section{Trial Registration: NCT04366817}

\section{Introduction}

The COVID-19 epidemic has had a major impact on societal organization and on the organization of healthcare systems. Both maternal and fetal outcomes have worsened during the pandemic and great disparities have been highlighted from country to country according to the level of resources. ${ }^{1} \mathrm{Few}$ studies have evaluated the impact of this crisis on the psychological well-being of women during the perinatal period. While an overall increase in anxiety in the prenatal and postnatal periods has been reported, studies of changes in postpartum depression (PPD) rates are scarce and have yielded conflicting results [1-4].

PPD varies greatly from one geographical area to another $[5,6]$. In France, the prevalence of PPD varies between 10 and $20 \%$ [7] and was close to $15 \%$ prior to the pandemic in the Parisian population [8]. The psychological well-being of pregnant women can influence their subjective experience of childbirth [9], their relationship with their partner [10], and mother-child bonding. Maternal stress during pregnancy may also cause emotional-neuro developmental disorders in the offspring [11-13]. 
During the first wave of the COVID-19 epidemic, most affected countries decided to restrict or even ban visits to hospitalized patients. In France, most maternity wards decided to allow the presence solely of the pregnant woman's partner in the delivery room and to prohibit visits during the postnatal hospital stay [14]. The separation of women from their relatives during this period exposed them to a greater psychological vulnerability $[6,15]$. Moreover, when women returned home, the implemented lockdown measures prevented visits by family members and limited face-to-face management by caregivers.

In anticipation of a situation of greater vulnerability related to the health crisis, the three maternity units of Sorbonne University, Paris, France, set up an organization to support women who gave birth during the first lockdown [14]. All women who gave birth in these units were offered a follow-up through telephone interviews with psychologists after they returned home. The interviews were conducted at Day 10 and 6-8 weeks postpartum, with the goal to identify patients at risk of developing PPD, and to organize, when necessary, flexible care plans for these mothers.

The main aim of our study was to compare the rate of PPD during the period of the first 2020 lockdown with the rate observed prior to the COVID-19 pandemic, and to examine factors associated with PPD. The secondary objectives were to study the impact on the couples' relationships, and the mother-child interaction.

\section{Methods}

\section{Study design and participants}

We conducted a prospective study involving women delivering a single live birth in one of the three maternities of the Sorbonne University during the first strict lockdown in France from $27^{\text {th }}$ March to $5^{\text {th }}$ May 2020. The study was conducted in accordance with the Helsinki declaration and was approved by the local ethics committee (Institutional Review Board lle de France II, approval 27042020 ClinicalTrial.gov ID: NCT04366817). All participants gave written informed consent. The inclusion criteria were: maternal age $\geq 18$ years, French social security registration, patients speaking and understanding French, and maternal post-delivery hospitalization in the conventional postnatal ward. The exclusion criteria were: women who did not speak French, mothers hospitalized in other units, and mothers of babies hospitalized in the Neonatal Intensive Care Unit.

Eligible participants were recruited by the midwives in the postnatal units and were offered the possibility of one telephone interview with a psychologist at Day 10 ( \pm 1 day) postpartum, and then another one 6 to 8 weeks later. Three attempts were made to call patients who failed to answer. The standardized interviews lasted approximately 45 minutes and were structured in two parts: (i) a structured interview with validated questionnaires, and (ii) a semi-structured interview about the mother's experience of childbirth, the maternity ward, conditions of discharge, and the first days/weeks at home with the baby and their partner. 


\section{Study measures}

We extracted sociodemographic and obstetrical data from the obstetrical records. These included: ( $I$ ) socioeconomic data (Marital/couple status, Educational Level, Profession, Current financial situation, Geographic origin), (ii) Obstetrical background: history of perinatal death, fetal malformation, intra-uterine growth retardation (IUGR), maternal-fetal infection, (iii) Maternal complications during the current pregnancy: hypertension, diabetes, hospitalization for threatened preterm labor, (iv) Maternal psychiatric background: history of PPD, history of mood or anxiety disorders, history of Post-Traumatic Stress Disorder (PTSD), and ( $v$ ) Specific psychosocial contexts: precarity, conflict within the couple, single parent, transgenerational familial history of obstetrical pathologies.

The following validated self-questionnaires were used during the interviews to assess postpartum depressive and post-traumatic symptoms, couple satisfaction and mother-child interactions:

- 1) The Edinburgh Postnatal Depression Scale (EPDS) [7], which is a 10-item questionnaire specific to the postpartum period and results in a depression score. For this study, we used the score as a continuous variable. An EPDS score > 12 was used to define a major risk of PPD, and an EPDS between 10 and 12 a mild to major risk.

- 2) The Perinatal Posttraumatic Stress Disorder Questionnaire (PPQ) [16] (validated French version [17]), which evaluates post-traumatic stress reactions of parents undergoing a childbirth with a high perinatal risk. It consists of 14 items, which refer to the DSM-V criteria of PTSD. A threshold of 6 was used to define a high risk of perinatal post-traumatic syndrome [16].

- 3) The couple's relationship (Dyadic Adjustment Scale; DAS-16) [18] is a self-questionnaire derived from the original 32-item DAS scale, which evaluates dyadic adjustment in the marriage [19]. The revised scale consists of 16 items relative to the quality of the couple's relationship and includes two dimensions: the degree of accordance (DA), and the quality of interaction (QI). The participants are asked to indicate their responses in relation to their experiences in the preceding 2 weeks, on a 6-point Likert scale. The score is calculated as a summation of all the responses, and ranges from 16 to 96 . Scores above 54 are considered to represent satisfactory adjustment. Some questions concern the frequency in which the couple laughs together, or the frequency with which the couple considers divorce. The last question asks, "In general, to what degree do you experience happiness in your relationship" on a scale from "extremely unhappy" to "extremely happy".

- 4) The Mother-Infant Bonding Scale (MIBS) [20] was initially developed to detect disturbances of maternal feelings towards their newborns. It is a short, simple questionnaire, used after birth in the maternity ward by different medical professionals: midwives, obstetricians, pediatricians, nurses. The scores range from 0 to 24 , with a higher score indicating an impaired mother-infant bond.

As part of this study, psychological or psychiatric support was offered to each woman with an EPDS score $>10$ and/or a PPQ score $>6$, or if the interview revealed clinical vulnerability indicators (e.g., 
expression of emotional distress, history of perinatal loss, separation from the partner) whatever the results of EPDS score.

\section{Statistical Analysis}

The study was designed to achieve $80 \%$ of power to detect at least a 5-point change in the proportion of major PPD compared to the expected proportion of $15 \%$ (15 vs. $20 \%$ ), considering two-sided alpha risk of $5 \%$ and $5 \%$ of dropout. Therefore, 452 women needed to be included.

Continuous variables were described as mean and standard deviation or median and interquartile range, depending on the distribution of the variable. Qualitative variables were expressed as numbers and proportions.

The proportion of patients with major PPD during follow-up, defined by an EPDS score $>12$, was calculated with its $95 \%$ confidence interval (exact method) and the exact binomial test was used to test the superiority of the proportion compared with the expected value of $15 \%$.

The association between depression and baseline characteristics was studied using logistic regression. Unadjusted analysis was performed to select variables at the $20 \%$ threshold taking into account missing values and relationships between variables or redundancy.

Post hoc analysis also assessed the association between baseline characteristics and PPD and/or posttraumatic symptoms during follow-up (EPDS $>12$ or PPQ $>6$ ).

Spearman rank correlation was used to determine post hoc correlations between scores. Missing values were not replaced. All tests were two-sided and a P-value $<0.05$ indicated statistical significance. Analyses were performed using SAS version 9.3, SAS institute Inc., Cary, USA.

\section{Results}

\section{Patient flow and recruitment}

Figure 1 details the patient flow chart of the study. A total of 231 women were eligible for inclusion, and 191 agreed to participate. Of these, 164 had a call interview on Day 10 and 138 at 6-8 weeks postpartum.

\section{General characteristics of the population}

The average maternal age was 34.1 years (range: 22-47 years) (Table 1). The education level of women was high. Most of the mothers (94.9\%) were in a couple and overall there was a low level of previous psychiatric or obstetrical history. Social vulnerability was present for $6.1 \%$ of the mothers (migration 3.1 $\%$, accommodation in a hostel $3.7 \%$ ). A context of conjugal conflict or violence was reported by $1.2 \%$ of the women. Finally, family isolation was reported by $26.7 \%$ of the mothers. Among the $15(9.3 \%)$ women with psychiatric or social vulnerability, six (3.7\%) had a history of psychiatric or neurologic pathology, 
three $(1.8 \%)$ of perinatal depression, six $(3.7 \%)$ of emotional or depression during the peripartum period, and two (1.2\%) had a history of PTSD.

\section{Obstetrical data and perinatal outcome}

Half of the patients were primiparous (Table 1). Maternal hypertension/preeclampsia or diabetes were observed in six $(3.7 \%)$ and $22(13.4 \%)$ of the women, respectively. Five $(3 \%)$ of the women had threatened preterm labor. COVID-19 infection occurred during the pregnancy in three women (uncomplicated maternal infection with no maternal hospitalization). Among these, one neonate had a positive COVID-19 polymerase chain reaction test (no neonatal signs of infection). The mean gestational age at delivery was 39 weeks (range: 34-42 weeks). Spontaneous labor occurred in 101 of the cases (69.7\%) and the overall vaginal delivery rate was $54.3 \%$ (Table 1 ). The partner was present at the delivery in $67 / 117$ cases (57.3\%). Of the 25 newborns ( $15.2 \%$ ) who presented with neonatal complications, 18 had neonatal hyperbilirubinemia. Neonatal hospitalization was required for 10 newborns (hyperbilirubinemia, extreme prematurity, feeding disorders).

Table 1: Socio-demographic and obstetrical maternal characteristics for all patients and by EPDS status 


\begin{tabular}{|c|c|c|c|c|c|c|c|}
\hline & \multicolumn{2}{|c|}{ All patients } & \multicolumn{2}{|c|}{ EPDS > 12 group } & \multicolumn{2}{|c|}{ EPDS $\leq 12$ group } & \multirow{2}{*}{$\begin{array}{l}\mathrm{p}- \\
\text { value }\end{array}$} \\
\hline & $\mathrm{n}^{*}$ & $\begin{array}{l}\mathrm{n}(\% \text { or mean } \pm \\
\text { sd); median } \\
\text { [interquartile } \\
\text { range] }\end{array}$ & $\mathrm{n}^{\star}$ & $\begin{array}{l}\mathrm{n}(\%) \text { or } \\
\text { mean } \pm \text { sd; } \\
\text { median } \\
\text { [interquartile } \\
\text { range] }\end{array}$ & $\mathrm{n}^{\star}$ & $\begin{array}{l}\mathrm{n}(\%) \text { or } \\
\text { mean } \pm \text { sd; } \\
\text { median } \\
\text { [interquartile } \\
\text { range] }\end{array}$ & \\
\hline \multicolumn{8}{|c|}{ Maternal socio-demographic characteristics } \\
\hline \multirow[t]{2}{*}{ Age (years) } & 164 & $34.1 \pm 4.8$ & 27 & $33.1 \pm 4.8$ & 137 & $34.4 \pm 4.8$ & $0.21^{3}$ \\
\hline & & $\begin{array}{l}34.0[31.0 ; \\
37.0]\end{array}$ & & $\begin{array}{l}33.0[29.0 ; \\
37.0]\end{array}$ & & $\begin{array}{l}34.0[31.0 ; \\
37.0]\end{array}$ & \\
\hline Origin & 154 & & 24 & & 130 & & $0.11^{2}$ \\
\hline Caucasian & & $91(59.1)$ & & $11(45.8)$ & & $80(61.5)$ & \\
\hline Sub-Saharan & & $18(11.7)$ & & $2(8.3)$ & & $16(12.3)$ & \\
\hline North african & & $25(16.2)$ & & $5(20.8)$ & & $20(15.4)$ & \\
\hline Asian & & $6(3.9)$ & & $2(8.3)$ & & $4(3.1)$ & \\
\hline South American & & $3(1.9)$ & & $2(8.3)$ & & $1(0.8)$ & \\
\hline Other & & $11(7.1)$ & & $2(8.3)$ & & $9(6.9)$ & \\
\hline In a couple & 156 & 148 (94.9) & 24 & $24(100)$ & 132 & $124(93.9)$ & $0.61^{2}$ \\
\hline Educational Level & 141 & & 23 & & 118 & & $0.69^{2}$ \\
\hline Non graduate & & $16(11.3)$ & & $3(13)$ & & $13(11)$ & \\
\hline Precarity & 161 & $6(3.7)$ & 26 & $1(3.8)$ & 135 & $5(3.7)$ & $1.00^{2}$ \\
\hline Socially isolated & 160 & $5(3.1)$ & 26 & $1(3.8)$ & 134 & $4(3.0)$ & $1.00^{2}$ \\
\hline $\begin{array}{l}\text { Isolated from } \\
\text { family }\end{array}$ & 30 & $8(26.7)$ & 1 & $1(100)$ & 29 & $7(24.1)$ & $0.27^{2}$ \\
\hline \multicolumn{8}{|l|}{ Psychiatric history } \\
\hline $\begin{array}{l}\text { Psychiatric or } \\
\text { neurologic }\end{array}$ & 163 & $6(3.7)$ & 27 & $1(3.7)$ & 136 & $5(3.7)$ & $1.00^{2}$ \\
\hline $\begin{array}{l}\text { Postpartum } \\
\text { depression }\end{array}$ & 163 & $3(1.8)$ & 27 & $1(3.7)$ & 136 & $2(1.5)$ & $0.42^{2}$ \\
\hline
\end{tabular}


Anxio-depressive $\quad 162 \quad 6(3.7)$

$27 \quad 1(3.7)$

$135 \quad 5(3.7)$

$1.00^{2}$

syndrome or thymic

pathology

PTSD

$1632(1.2)$

$27 \quad 0$

$136 \quad 2(1.5)$

$1.00^{2}$

\section{Specific \\ psychosocial \\ contexts}

$\begin{array}{lccccccc}\begin{array}{l}\text { Conflict within } \\ \text { couple }\end{array} & 162 & 2(1.2) & 27 & 0 & 135 & 2(1.5) & 1.00^{2} \\ \begin{array}{l}\text { Transgenerational } \\ \text { familial history of } \\ \text { obstetrical } \\ \text { pathologies }\end{array} & 24 & 1(4.2) & 0 & & 24 & 1(4.2) & \\ \begin{array}{l}\text { Psychic } \\ \text { vulnerability }\end{array} & 162 & 15(9.3) & 27 & 3(11.1) & 135 & 12(8.9) & 0.72^{2} \\ \begin{array}{l}\text { Psychosocial } \\ \text { vulnerability }\end{array} & 163 & 10(6.1) & 27 & 1(3.7) & 136 & 9(6.6) & \\ & & & & & & & \end{array}$

\section{Obstetrical history}

\begin{tabular}{lccccccc}
$\begin{array}{l}\text { Pathological } \\
\text { obstetrical history }\end{array}$ & 161 & $10(6.2)$ & 26 & $1(3.8)$ & 135 & $9(6.7)$ & $1.00^{2}$ \\
\hline Perinatal death & 163 & $3(1.8)$ & 27 & 0 & 136 & $3(2.2)$ & $1.00^{2}$ \\
TOP & 163 & $2(1.2)$ & 26 & 0 & 137 & $2(1.5)$ & $1.00^{2}$ \\
\hline Fetal malformation & 163 & $1(0.6)$ & 27 & 0 & 136 & $1(0.7)$ & $1.00^{2}$ \\
IUGR & 164 & $6(3.7)$ & 27 & $1(3.7)$ & 137 & $5(3.6)$ & $1.00^{2}$ \\
$\begin{array}{l}\text { Maternal-fetal } \\
\text { infection }\end{array}$ & 162 & 0 & & & & &
\end{tabular}

\section{Obstetrical} characteristics

\begin{tabular}{|lccccccc|} 
Primiparous & 164 & $82(50.0)$ & 27 & $15(55.6)$ & 137 & $67(48.9)$ & $0.53^{1}$ \\
$\begin{array}{l}\text { Psychiatric or } \\
\text { psychological } \\
\text { follow-up }\end{array}$ & 160 & $13(8.1)$ & 25 & $3(12.0)$ & 135 & $10(7.4)$ & $0.47^{2}$ \\
\hline $\begin{array}{l}\text { Hypertension or } \\
\text { yyph }\end{array}$ & 164 & $6(3.7)$ & 27 & $4(14.8)$ & 137 & $2(1.5)$ & $0.01^{2}$
\end{tabular}




\begin{tabular}{lccccccc} 
pre-eclampsia & & & & & & \\
Diabetes & 164 & $22(13.4)$ & 27 & 0 & 137 & $22(16.1)$ & $0.03^{2}$ \\
\hline SGA fetus & 162 & $8(4.9)$ & 26 & $2(7.7)$ & 136 & $6(4.4)$ & $0.62^{2}$ \\
\hline $\begin{array}{l}\text { Premature delivery } \\
\text { threat }\end{array}$ & 164 & $5(3.0)$ & 27 & $3(11.1)$ & 137 & $2(1.5)$ & $0.03^{2}$ \\
$\begin{array}{l}\text { Maternal COVID-19 } \\
\text { infection }\end{array}$ & 164 & $3(1.8)$ & 27 & $2(7.4)$ & 137 & $1(0.7)$ & $0.07^{2}$ \\
\hline
\end{tabular}

\section{Delivery}

\begin{tabular}{|c|c|c|c|c|c|c|c|}
\hline GA at delivery (WG) & 164 & $\begin{array}{l}39.3 \pm \\
1.4 \\
39.0[39.0 \\
40.0]\end{array}$ & 27 & $\begin{array}{l}39.0 \pm 1.7 \\
39.0[38.0 ; \\
40.0]\end{array}$ & 137 & $\begin{array}{l}39.3 \pm 1.3 \\
39.0[39.0 ; \\
40.0]\end{array}$ & $0.45^{3}$ \\
\hline $\begin{array}{l}\text { Partner present at } \\
\text { delivery }\end{array}$ & 117 & $67(57.3)$ & 19 & $9(47.4)$ & 98 & $58(59.2)$ & $0.34^{1}$ \\
\hline Mode of delivery & 164 & & 27 & & 137 & & $0.08^{2}$ \\
\hline $\begin{array}{l}\text { Spontaneous } \\
\text { vaginal }\end{array}$ & & $89(54.3)$ & & $9(33.3)$ & & $80(58.4)$ & \\
\hline Assisted vaginal & & $32(19.5)$ & & 7 (25.9) & & $25(18.2)$ & \\
\hline $\begin{array}{l}\text { Emergency c- } \\
\text { section }\end{array}$ & & $25(15.2)$ & & $7(25.9)$ & & $18(13.1)$ & \\
\hline Elective c-section & & $18(11.0)$ & & $4(14.8)$ & & $14(10.2)$ & \\
\hline Episiotomy & 164 & $12(7.3)$ & 27 & $2(7.4)$ & 137 & $10(7.3)$ & 1.00 \\
\hline Perineal tear & 164 & $87(53.0)$ & 27 & $10(37.0)$ & 137 & $77(56.2)$ & $0.07^{1}$ \\
\hline $\begin{array}{l}\text { Postpartum } \\
\text { hemorrhage }\end{array}$ & 164 & $15(9.1)$ & 27 & $3(11.1)$ & 137 & $12(8.8)$ & $0.72^{2}$ \\
\hline \multicolumn{8}{|l|}{ Neonate } \\
\hline $\begin{array}{l}\text { Neonatal } \\
\text { complications }\end{array}$ & 164 & 25 (15.2) & 27 & $9(33.3)$ & 137 & $16(11.7)$ & 0.008 \\
\hline $\begin{array}{l}\text { Neonatal COVID-19 } \\
\text { infection }\end{array}$ & 162 & $1(0.6)$ & 27 & $1(3.7)$ & 135 & 0 & $0.17^{2}$ \\
\hline
\end{tabular}


* available data

sd: standard deviation

PTSD: post-traumatic stress disorder

TOP: termination of pregnancy

IUGR: intra uterine growth retardation

SGA: small for gestational age

GA: gestational age WG: weeks of gestation

\section{Maternal psychological outcome}

Major PPD (EPDS score > 12) was observed in 27/164 women 16.5\% [95\% Cl: $11.14-23.04$ ] either at Day 10 or 6-8 weeks postpartum. This was similar to the rate of $15 \%$ reported prior to the pandemic $(p=0.6)$. Mild to major depression (EPDS $>10$ at one of the two telephone interviews) was observed in 40/164 women $(24.4 \%)$ [95\%Cl:18.03 - 31.70].

Maternal hypertension/preeclampsia $(p=0.007)$, emergency cesarean section $(p=0.03)$ and neonatal complications $(p=0.008)$ were significantly associated with an EPDS $>12$ in both univariate and multivariate analysis (OR=10 [95\% Cl: $1.5-68.7], \mathrm{OR}=4.09$ [95\% Cl: $1.2-14.1]$, OR=4.02 [95\%Cl: $1.4-$ 11.6], respectively) (Table 2). Threatened preterm labor was significantly associated with PPD $(p=0.03)$ and was an associated factor with maternal hypertension/preeclampsia.

Table 2: Multivariate analysis of risk factors for postpartum depression (EPDS > 12) 


\begin{tabular}{|lllll|}
\hline & OR $[95 \% \mathrm{Cl}]$ & P-value & AOR $[95 \% \mathrm{Cl}]$ & P-value \\
\hline Hypertension or pre-eclampsia & $11.74[2.03-67.82]$ & 0.01 & $10.01[1.46-68.67]$ & 0.02 \\
\hline Threatened preterm labor & $8.44[1.34-53.19]$ & 0.02 & & \\
\hline Maternal COVID-19 infection & $10.88[0.95-124.6]$ & 0.06 & & \\
\hline Delivery & & & & \\
\hline Spontaneous vaginal & Reference & & Reference & \\
\hline Assisted vaginal & $2.49[0.84-7.37]$ & 0.10 & $2.29[0.73-7.22]$ & 0.16 \\
\hline Emergency c-section & $3.46[1.14-10.51]$ & 0.03 & $4.09[1.18-14.13]$ & 0.03 \\
\hline Elective c-section & $2.54[0.69-9.39]$ & 0.16 & $2.48[0.61-10.08]$ & 0.20 \\
\hline Neonatal complications & $3.78[1.46-9.83]$ & 0.01 & $4.02[1.40-11.55]$ & 0.02 \\
\hline
\end{tabular}

EPDS: Edinburgh Postnatal Depression Scale

OR [95\% Cl]: Odds ratio [95\% Confidence Interval]

AOR: Adjusted Odds ratio

Mean scores of satisfaction in the couple were high and stable between the two interviews: the DAS-16 total score was $62.7( \pm 8.4)$ at Day 10 , and $62.6( \pm 9.1)$ at 6-8 weeks postpartum. The perception of a good relationship in the couple (DAS total score, and DA and QI sub-score) was negatively correlated with the EPDS scores (DAS total $x$ EPDS, $\rho=-0.22, p=0.01$; DA $x$ EPDS; $p=-0.25389, p=0.005$; QI $x$ EPDS: $\rho=-0.15329 p=0.0932)$. Some maternal-newborn interactions were slightly impaired with a mean MIBS score of $1.6( \pm 1.7)$ at Day 10 and $1.3( \pm 1.4)$ at $6-8$ weeks. In the French MIBS validation study, an absence of interaction disorder represented a score of 0 to 1 (20). The MIBS scores were correlated with the global EPDS and PPQ score at Day $10(\rho=0.32, p=0.0003$, and $\rho=0.20, p=0.02$, respectively). PPD (EPDS $>12$ at Day 10) and post-partum traumatic symptoms (PPQ scores) were also strongly correlated $(\rho=0.6, p<0.0001)$.

Factors associated with an increased risk of maternal depression and post-traumatic stress syndrome

Thirty-four (20.7\%) patients had an EPDS $>12$ or PPQ $>6$. The variables significantly associated with depressive-anxiety symptoms were: the geographic origin of the mother $(p=0.04)$, maternal hypertension/preeclampsia $(p=0.02)$, partner not present at delivery $(p=0.05)$, neonatal complications 
$(p=0.04)$, and maternal COVID-19 infection during the pregnancy $(p=0.008)$. Adjusted multivariate analysis found that the variables that were significantly associated with post traumatic-depressive symptoms were: a previous child hospitalization ( $\mathrm{OR}=7.49$ [95\%Cl: 1.61-34.94] $\mathrm{p}=0.010)$, neonatal complications ( $\mathrm{OR}=3$ [95\%Cl: $1.08-8.35] \mathrm{p}=0.04)$, hypertension/preeclampsia $(\mathrm{OR}=8.17$ [95\% Cl: $1.245-$ 3.70] $p=0.03)$ and emergency cesarean section $(\mathrm{OR}=2.08[95 \% \mathrm{Cl}: 1.10-10.85] \mathrm{p}=0.05)($ Table 3$)$.

\section{Table 3: Multivariate analysis of risk factors associated with EPDS $>12$ and/or PPQ $>6$}

\begin{tabular}{|lllll|}
\hline & OR $[95 \% \mathrm{Cl}]$ & P-value & AOR $[95 \% \mathrm{Cl}]$ & P-value \\
\hline Previous child hospitalization & $4.13[0.98-17.48]$ & 0.05 & $7.49[1.61-34.94]$ & 0.01 \\
\hline Hypertension or pre-eclampsia & $8.40[1.47-48.02]$ & 0.02 & $8.17[1.24-53.70]$ & 0.03 \\
\hline Threatened preterm labor & $6.09[0.98-38.05]$ & 0.05 & & \\
\hline Mode of Delivery & & & & \\
\hline Spontaneous vaginal & Reference & & Reference & \\
\hline Assisted vaginal & $1.90[0.70-5.13]$ & 0.06 & $2.19[0.75-6.39]$ & 0.15 \\
\hline Emergency c-section & $2.68[0.96-7.48]$ & 0.03 & $3.45[1.10-10.85]$ & 0.03 \\
\hline Elective c-section & $2.19[0.67-7.18]$ & 0.20 & $2.34[0.65-8.50]$ & 0.20 \\
\hline Neonatal complications & $2.52[1.00-6.35]$ & 0.05 & $3.00[1.08-8.35]$ & 0.04 \\
\hline
\end{tabular}

EPDS: Edinburgh Postnatal Depression Scale

PPQ: Post-traumatic Stress Disorder Questionnaire

OR [95\% Cl]: Odds ratio [95\% Confidence Interval]

AOR: Adjusted Odds ratio

\section{Vulnerability screening and psychological monitoring}

Psychological support was offered to $71 / 164$ women (42\%), including 46 patients (28\%) with an EPDS score $>10$ and/or PPQ $>6$. In the other 25 cases, the scores did not reach the risk thresholds, but the free speech interviews revealed clinical indicators of vulnerability. Psychological or psychiatric interventions were organized for 21 of the 71 women. In the other 50 patients, a follow-up was proposed based on regular phone calls by psychologists. Among these, an improvement was observed in 20 cases with no sign of depression at 6-8 weeks. For the remaining 30 patients, 18 opted for outpatient psychological support and 12 were lost to follow-up. 


\section{Discussion}

\section{Main findings}

The rate of $16.5 \%$ of women with major PPD (EPDS score > 12) we found either at Day 10 or 6-8 weeks postpartum was similar to the one observed in our population prior to the COVID-19 pandemic [8]. The risk factors associated with major PPD in our population were not specifically associated with the COVID19 pandemic. Depressive and/or post-traumatic symptoms were observed in $20.8 \%$ of the cases. To support women during this period of increased vulnerability, we offered an adapted psychological followup to $71 / 164$ (43\%) of the mothers. This support led to clinical improvement in 20 cases. In the event of emotional post-partum impact, the mother-child interaction, as captured by the MIBS, and the couple's adjustment, as captured by the DAS, were also impaired.

\section{Strengths and limitations}

One of the strengths of our study lies in its prospective design. Furthermore, we did not rely solely on selfquestionnaires during the calls but included a time of free exchange with a psychologist to increase the chances of picking up on signs of psychological vulnerability. In addition, we screened patients at risk of PPD at two separate times up to 6-8 weeks postpartum. Finally, psychological support was offered to improve the immediate psychological outcome of the patients. One of the weaknesses of the study is related to the fact that we did not obtain the calculated sample size for the study. This limitation was partly due to a delay in obtaining regulatory approval, which reduced our inclusion period to 6 weeks. In addition, we were unable to capture the reason for which some patients who gave birth during this period declined to participate in the study. Another limitation is the $16 \%$ attrition rate we observed between the two separate times of evaluation. Finally, we were unable to complete the follow-up for all the 71 women in whom psychological vulnerability was identified at Day 10.

\section{Comments}

Contrary to several studies carried out throughout the world, we did not observe a significant increase in the PPD rate during the period of the first strict lockdown of 2020. Our PPD rate of $16 \%$ apparently contradicts several recent reports supporting an increased risk of perinatal depression related to the COVID-19 pandemic with rates ranging between $21 \%$ and $56.9 \%[2,21-24]$. Our rate is closer to the rate of $12 \%$ found in the Netherlands, even if this rate was twice as high as their pre-pandemic rate [25], and higher than the 6.4\% reported in Silverman et al.'s study in New York City (Mount Sinai Health System Sites), USA [26]. It should be noted that most of the studies, often performed at different times during the postpartum period, relied on self-completed online questionnaires, which may introduce a bias.

Furthermore, it should be noted that the EPDS questionnaire is merely a screening method, which does not replace a clinical diagnosis of depression [27]. It is also difficult to compare studies because of the heterogenous characteristics of the studied populations, including the socio-economic level. However, Chmielewska et al. explored this large heterogeneity between studies in their meta-analysis [1]. The subgroup analyses according to a country's income status showed a statistically significant increase in 
mean EPDS scores in low- and middle-income countries but not in high-income countries. We found that the rate of anxiety-depressive disorders associated with post-traumatic stress was $20.7 \%$. This is in line with the increase in anxiety reported both during pregnancy and in the postpartum period in the two previously cited meta-analyses $[1,5]$.

The fact that we did not observe an increase in the PPD rate in this period could also be related to the call program we set up during the first lockdown period. By calling the mothers at Day 10 and then at $6-8$ weeks, we were able to identify psychic vulnerability in 71/164 patients. We consequently organized conventional psychological care programs for 21 patients and regular phone calls by psychologists with the remaining 50, which resulted in an improvement in the psychological state for at least 20 mothers.

Variables associated with increased PPD from univariate analysis include well-known risk factors which were unrelated to the pandemic such as sociodemographics (low income, migration $[12,28]$ ), somatic conditions (hypertension/preeclampsia [29, 30]), and childbirth complications [31, 32]. Although hypertension was associated with an excess risk of complications in case of COVID infection early on in the pandemic, it is impossible to link the hypertension factor with the crisis. Similarly, the impact of the partner's absence at the delivery was not associated in our study with an increased risk of PPD. However, it did appear to be associated with an increased risk of anxiety-depressive disorders. Finally, an emergency cesarean section was associated with an increased risk of PPD and post-traumatic syndrome. Even if this factor was already known, it could be considered to be related to the pandemic since partners were not allowed in the operating rooms during the period of the first lockdown in our maternity unit, as in most units in France.

\section{Conclusion}

In our population we did not observe an increased rate of major PPD during the first COVID-19 lockdown period. However, anxiety-depressive signs were identified in up to $20 \%$ of our patients. The organization we set up consisting of an evaluation by psychologists at two time points during the postpartum period enabled us to support the mothers thereby limiting the psychological consequences of the social restriction measures in place.

\section{Abbreviations}

PPD postpartum depression

EPDS Edinburgh Posnatal Depression Scale

PPQ Perinatal Post-traumatic Stress Disorder Questionnaire

$\mathrm{Cl}$ confidence Interval

OR odds ratio 
IUGR intra-uterine growth restriction

PTSD post-traumatic stress disorder

DAS Dyadic Adjustment Scale

DA degree of accordance

QI quality if interaction

MIBS Mother-Infant Bonding Scale

USA United States of America

\section{Declarations}

\section{Ethics approval}

The study was conducted in accordance to the Helsinki declaration and was approved by ethics committee (Institutional Review Board Ile de France II, agreement 27042020). The study was also registered to ClinicalTrial.gov (ID: NCT04366817). All participants gave written informed consent.

\section{Consent for publication}

Not applicable

\section{Availability of data and materials}

The data used and analyzed during the current study are available from the promotor, APHP.

\section{Competing interests}

The authors declare that they have no conflict of interest.

\section{Funding and Sponsorship}

The sponsor was Assistance Publique - Hôpitaux de Paris (Délégation à la Recherche Clinique et à I'Innovation).

This study was supported by the PHRC Program, covid-19-20-0088, from the French Ministry of Health.

\section{Authors' contributions:}

SVS and JMJ contributed to the conception and the design of the study. SV-S, PM, CL, LB and MR collected data. AR realized statistical analysis. DC, SVS JMJ contributed to interpretation of results. SVS, 
JMJ, DC and AR drafted the manuscript and revised it. All the authors have read and approved the final manuscript.

\section{Acknowledgements}

We thank the women who accepted to participate in the study.

We would also like to thank Juliette Deron, Enola Saleur, Jaqueline Wendland, Laura Roman-Teboul, France Trevisan, Isabelle Hagbarth, Laure Woestelandt, Berengere Terreau, Morgane Roman, Margaux Piollet, Meya Ibnolmobarak, Amélie Bion from the Child Psychiatry Departement of Pitié Salpêtriere, Paris who called all the women and help them to manage with this so special period.

We thank Leopoldine Legrain and Dr Melissa Montil from the Clinical Research Center of East of Paris (CRC-Est), Saint-Antoine University Hospital (AP-HP) for their logistic support.

\section{References}

1. Chmielewska B, Barratt I, Townsend R, Kalafat E, van der Meulen J, Gurol-Urganci I, et al. Effects of the COVID-19 pandemic on maternal and perinatal outcomes: a systematic review and metaanalysis. Lancet Glob Health. 2021 Jun;9(6):e759-72.

2. Wu Y, Zhang C, Liu H, Duan C, Li C, Fan J, et al. Perinatal depressive and anxiety symptoms of pregnant women during the coronavirus disease 2019 outbreak in China. Am J Obstet Gynecol. 2020 Aug;223(2):240.e1-240.e9.

3. Hessami K, Romanelli C, Chiurazzi M, Cozzolino M. COVID-19 pandemic and maternal mental health: a systematic review and meta-analysis. J Matern-Fetal Neonatal Med Off J Eur Assoc Perinat Med Fed Asia Ocean Perinat Soc Int Soc Perinat Obstet. 2020 Nov 1;1-8.

4. Fallon V, Davies SM, Silverio SA, Jackson L, De Pascalis L, Harrold JA. Psychosocial experiences of postnatal women during the COVID-19 pandemic. A UK-wide study of prevalence rates and risk factors for clinically relevant depression and anxiety. J Psychiatr Res. 2021 Apr;136:157-66.

5. Shorey S, Chee CYI, Ng ED, Chan YH, Tam WWS, Chong YS. Prevalence and incidence of postpartum depression among healthy mothers: A systematic review and meta-analysis. J Psychiatr Res. 2018 Sep;104:235-48.

6. Woody CA, Ferrari AJ, Siskind DJ, Whiteford HA, Harris MG. A systematic review and meta-regression of the prevalence and incidence of perinatal depression. J Affect Disord. 2017 Sep;219:86-92.

7. Teissèdre $F$, Chabrol $H$. Detecting women at risk for postnatal depression using the Edinburgh Postnatal Depression Scale at 2 to 3 days postpartum. Can J Psychiatry Rev Can Psychiatr. 2004 Jan;49(1):51-4.

8. Gaillard A, Le Strat Y, Mandelbrot L, Keïta H, Dubertret C. Predictors of postpartum depression: prospective study of 264 women followed during pregnancy and postpartum. Psychiatry Res. 2014 Feb 28;215(2):341-6. 
9. Molgora S, Accordini M. Motherhood in the Time of Coronavirus: The Impact of the Pandemic Emergency on Expectant and Postpartum Women's Psychological Well-Being. Front Psychol. 2020;11:567155.

10. Dennis C-L, Brown HK, Brennenstuhl S. The Postpartum Partner Support Scale: Development, psychometric assessment, and predictive validity in a Canadian prospective cohort. Midwifery. 2017 Nov;54:18-24.

11. Murray L, Cooper P. Effects of postnatal depression on infant development. Arch Dis Child. 1997 Aug;77(2):99-101.

12. Beck CT. Predictors of postpartum depression: an update. Nurs Res. 2001 Oct;50(5):275-85.

13. Abdoli A, Falahi S, Kenarkoohi A, Shams M, Mir H, Jahromi MAM. The COVID-19 pandemic, psychological stress during pregnancy, and risk of neurodevelopmental disorders in offspring: a neglected consequence. J Psychosom Obstet Gynaecol. 2020 Sep;41(3):247-8.

14. Viaux S, Maurice P, Cohen D, Jouannic JM. Giving birth under lockdown during the COVID-19 epidemic. J Gynecol Obstet Hum Reprod. 2020 Jun;49(6):101785.

15. O'hara MW, Swain AM. Rates and risk of postpartum depression-a meta-analysis. Int Rev Psychiatry. 1996 Jan 1;8(1):37-54.

16. Quinnell FA, Hynan MT. Convergent and discriminant validity of the perinatal PTSD questionnaire (PPQ): a preliminary study. J Trauma Stress. 1999 Jan;12(1):193-9.

17. Muller-Nix C, Forcada-Guex M, Pierrehumbert B, Jaunin L, Borghini A, Ansermet F. Prematurity, maternal stress and mother-child interactions. Early Hum Dev. 2004 Sep;79(2):145-58.

18. Antoine P, Christophe V, Nandrino J-L. [Dyadic Adjustment Scale: clinical interest of a revision and validation of an abbreviated form]. L'Encephale. 2008 Jan;34(1):38-46.

19. Spanier GB. The measurement of marital quality. J Sex Marital Ther. 1979;5(3):288-300.

20. Bienfait M, Maury M, Haquet A, Faillie J-L, Franc N, Combes $C$, et al. Pertinence of the self-report mother-to-infant bonding scale in the neonatal unit of a maternity ward. Early Hum Dev. 2011 Apr;87(4):281-7.

21. Sun G, Wang Q, Lin Y, Li R, Yang L, Liu X, et al. Perinatal Depression of Exposed Maternal Women in the COVID-19 Pandemic in Wuhan, China. Front Psychiatry. 2020;11:551812.

22. Zanardo V, Manghina V, Giliberti L, Vettore M, Severino L, Straface G. Psychological impact of COVID19 quarantine measures in northeastern Italy on mothers in the immediate postpartum period. Int $\mathrm{J}$ Gynaecol Obstet Off Organ Int Fed Gynaecol Obstet. 2020 Aug;150(2):184-8.

23. An R, Chen X, Wu Y, Liu J, Deng C, Liu Y, et al. A survey of postpartum depression and health care needs among Chinese postpartum women during the pandemic of COVID-19. Arch Psychiatr Nurs. 2021 Apr;35(2):172-7.

24. Ostacoli L, Cosma S, Bevilacqua F, Berchialla P, Bovetti M, Carosso AR, et al. Psychosocial factors associated with postpartum psychological distress during the Covid-19 pandemic: a cross-sectional study. BMC Pregnancy Childbirth. 2020 Nov 18;20(1):703. 
25. Vacaru S, Beijers R, Browne PD, Cloin M, van Bakel H, van den Heuvel MI, et al. The risk and protective factors of heightened prenatal anxiety and depression during the COVID-19 lockdown. Sci Rep. 2021 Oct 12;11(1):20261.

26. Silverman ME, Burgos L, Rodriguez ZI, Afzal O, Kalishman A, Callipari F, et al. Postpartum mood among universally screened high and low socioeconomic status patients during COVID-19 social restrictions in New York City. Sci Rep. 2020 Dec 24;10(1):22380.

27. Cox JL, Holden JM, Sagovsky R. Detection of postnatal depression. Development of the 10-item Edinburgh Postnatal Depression Scale. Br J Psychiatry J Ment Sci. 1987 Jun;150:782-6.

28. Fellmeth G, Fazel M, Plugge E. Migration and perinatal mental health in women from low- and middle-income countries: a systematic review and meta-analysis. BJOG Int J Obstet Gynaecol. 2017 Apr;124(5):742-52.

29. Koutra K, Vassilaki M, Georgiou V, Koutis A, Bitsios P, Kogevinas M, et al. Pregnancy, perinatal and postpartum complications as determinants of postpartum depression: the Rhea mother-child cohort in Crete, Greece. Epidemiol Psychiatr Sci. 2018 Jun;27(3):244-55.

30. Roberts L, Davis GK, Homer CSE. Depression, Anxiety, and Post-traumatic Stress Disorder Following a Hypertensive Disorder of Pregnancy: A Narrative Literature Review. Front Cardiovasc Med. 2019;6:147.

31. Dekel S, Ein-Dor T, Dishy GA, Mayopoulos PA. Beyond postpartum depression: posttraumatic stressdepressive response following childbirth. Arch Womens Ment Health. 2020 Aug;23(4):557-64.

32. Thiel F, Berman Z, Dishy GA, Chan SJ, Seth H, Tokala M, et al. Traumatic memories of childbirth relate to maternal postpartum posttraumatic stress disorder. J Anxiety Disord. 2021 Jan;77:102342.

\section{Figures}




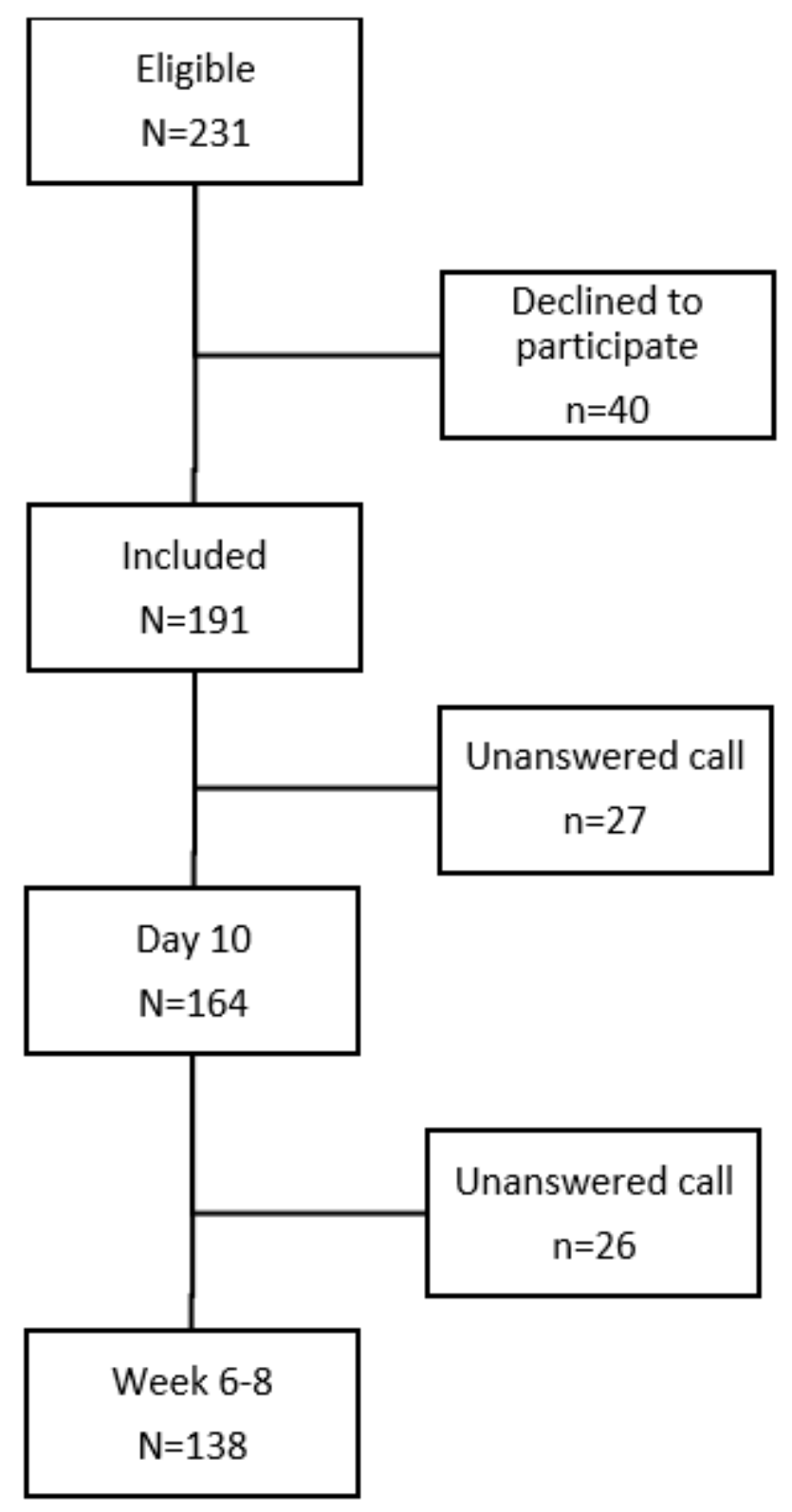

Figure 1

Flow chart of the study 